\title{
CURRENT SITUATION OF NUCLEAR MEDICINE IN SAUDI ARABIA
}

\begin{tabular}{ll}
\hline Radiology & \\
Abdullah Alqarni & Nuclear Medicine Unit, Prince Sultan Medical Military City, Riyadh, Saudi Arabia \\
\hline Hussein Farghaly & Nuclear Medicine Unit, Prince Sultan Medical Military City, Riyadh, Saudi Arabia \\
\hline Hatem Nasr* & $\begin{array}{l}\text { Nuclear Medicine Unit, Prince Sultan Medical Military City, Riyadh, Saudi Arabia } \\
* \text { Corresponding Author }\end{array}$ \\
\hline
\end{tabular}

\section{ABSTRACT}

Objectives: A survey of nuclear medicine services in Saudi Arabia carried out to provide a baseline data information about the practice of Nuclear medicine (NM) by the beginning of 2018 .

Methods: An electronic questionnaire was sent to every NM department in Saudi Arabia. Information requested included the equipment, manpower and type of examinations performed.

Results: All the 58 NM services in Saudi Arabia had responded to the questionnaire by October 2018. The overall functioning manpower included 65 NM physicians, 190 NM technologists, 41 nuclear physicists, and only 9 radio pharmacists. At the end of year 2017 there were 21 PET/CT machines in Saudi Arabia (15 machines in Riyadh, 4 in Dammam and 2 in Jeddah), 55 SPECT/CT, 35 SPECT and Gamma camera Machines, and 77 DEXA machines. When adjusted to population, we found 0.6 PET/CT Unit per $1 \mathrm{M}$ people, 3.4 total units (PET and SPECT Cameras) per $1 \mathrm{M} \mathrm{people.}$

Conclusion: The need for reorganizing the distribution of nuclear medicine services including the cyclotrons to cover the whole kingdom equally. Activation of Saudi Society of Nuclear Medicine (SSNM) is mandatory for establishing well recognized Nuclear medicine residency training program including other academic and scientific activities.

\section{KEYWORDS}

\section{Nuclear Medicine, Saudi Arabia, Status}

\section{INTRUDUCTION:}

Nuclear medicine is a multi-disciplinary specialty that had developed dramatically worldwide over the past 50 years. Nuclear medicine uses instrumentation and radiopharmaceuticals to study physiological processes and organs function, providing information that cannot be acquired with other conventional morphological imaging technologies. Nuclear medicine procedures are non-invasive modalities used not only for diagnosis, staging and follow up of various diseases but also for therapy in some conditions (1).

Nowadays, the hybrid imaging like Positron Emission TomographyComputed Tomogram Scan (PET/CT), Single-Photon Emission Computed Tomography-Computed Tomogram (SPECT/CT) and more recently Positron Emission Tomography-Magnetic Resonance Imaging (PET/MRI) scan play a big role in the development of Nuclear medicine practice. Hybrid imaging combines two or more imaging modalities to take advantage of the characteristics of each. Therefore, hybrid imaging can simultaneously provide high anatomic detail, metabolic and/or physiological function, enabling more accurate diagnosis, better care pathways, refining treatment regimes, and improving patient outcomes.

As a part of the global nuclear medicine adventure, Saudi Arabia has made great strides for the developing of nuclear medicine practice. The Nuclear medicine services in Saudi Arabia is provided by many departments through Ministry of Health $(\mathrm{MOH})$, other governmental sectors hospitals(GSH) including; "Armed forces medical services department, Medical Services of National Guard, Medical Services of Ministry of Interior, King Faisal Specialist Hospitals and Research centers, University Hospitals", and multiple Private Hospitals (PH). These nuclear medicine services and centers distributed all over the kingdom through 13 administrative areas.

\section{METHOD:}

An electronic questionnaire was sent to every nuclear medicine department in Saudi Arabia. Information requested included the equipment, manpower and different examinations. Most of nuclear medicine services in Saudi Arabia had responded to the questionnaire by October 2018 .

\section{RESULTS AND DISCUSSION:}

Nuclear Medicine centers and Manpower:

The integration of NM services in Saudi Arabia was one of the first amongst the Middle East countries and has a superb economic and technical advantages due to the incredible support and funding through both governmental and private sectors.
In Saudi Arabia with population of about 33 millions by the beginning of the year 2018 (2), we found that there are 58 centers of NM (7 of them non-functioning); 25 centers $(43 \%)$ operated by Ministry of Health, 19 centers (33\%) operated by other governmental sectors, and 14 centers $(24 \%)$ by private hospitals. These centers are functioning with manpower of 65 nuclear medicine physicians (55consultants and 10 registrar and senior registrars). There are $186 \mathrm{NM}$ technologists in Saudi Arabia, most of them seniors with master degrees and 41 nuclear physicist and only 9 radio pharmacists. If we compare that to Nuclear Medicine in France of 65 million population at the end of 2011with 600 NM physicians working in 220 centers (3), the NM in Saudi Arabia of 33 million population by 2018 is considered a promising developing market with great potential for future growth.

\section{The Equipment:}

At the end of year 2017 there were 21 PET/CT machines in Saudi Arabia (15 machines in Riyadh, 4 in Dammam and 2 in Jeddah), 55 SPECT/CT machines, 35 SPECT and Gamma camera machines, and 77 DEXA machines. There were many other DEXA machines in other departments like radiology and private centers not included in our study, table (1). When we adjusted that for population we found 0.64 PET/CT unit per $1 \mathrm{M}$ people, 3.3 total units (PET and SPECT Cameras) per $1 \mathrm{M}$ people, (Fig1).

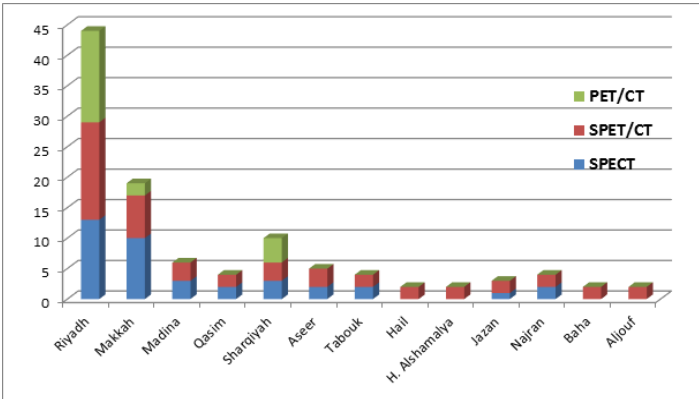

Figure1: Distribution of NM equipment among the 13 administrative regions within Saudi Arabia, not including DEXA.

\section{Examinations:}

Across Saudi Arabia a total of 68135 examinations were done in all services of nuclear medicine including all types of modalities during 2017. 
Table 1: Distribution of NM services including equipment and human resources in different regions. Hosp; hospitals, Ctr; center, Dr; doctors, Tec; technologists.

\begin{tabular}{|l|c|c|c|c|c|c|c|c|c|c|c|}
\hline & & & & \multicolumn{7}{|c|}{ EQUIMENT \& HUMAN RESOURCE } \\
\hline Region & Population & Hosp & Beds & $\begin{array}{c}\text { NM } \\
\text { Ctr }\end{array}$ & BMD & SPECT & SPET/CT & PET/CT & Total & Dr & Tec \\
\hline Riyadh & 8002100 & 47 & 7937 & 15 & 16 & 13 & 19 & 15 & 63 & 27 & 91 \\
\hline Makkah & 8325304 & 41 & 8457 & 12 & 15 & 10 & 9 & 2 & 36 & 15 & 49 \\
\hline Madina & 2080436 & 20 & 2818 & 5 & 5 & 3 & 6 & 0 & 14 & 3 & 6 \\
\hline Qasim & 1387996 & 18 & 2809 & 4 & 4 & 1 & 4 & 0 & 9 & 2 & 11 \\
\hline Sharqiyah & 4780619 & 35 & 6161 & 8 & 8 & 3 & 5 & 4 & 20 & 11 & 17 \\
\hline Aseer & 2164172 & 27 & 3050 & 4 & 6 & 2 & 4 & 0 & 12 & 2 & 4 \\
\hline Tabouk & 890922 & 11 & 1220 & 2 & 4 & 2 & 1 & 0 & 7 & 2 & 4 \\
\hline Hail & 684619 & 12 & 1175 & 2 & 3 & 0 & 1 & 0 & 4 & 0 & 0 \\
\hline Shamalya & 359235 & 9 & 1310 & 1 & 3 & 0 & 1 & 0 & 4 & 0 & 0 \\
\hline Jazan & 1533680 & 21 & 2225 & 2 & 3 & 1 & 2 & 0 & 6 & 2 & 2 \\
\hline Sajran & 569332 & 11 & 1200 & 1 & 4 & 0 & 1 & 0 & 5 & 1 & 2 \\
\hline Baha & 466384 & 10 & 1165 & 1 & 3 & 0 & 1 & 0 & 4 & 0 & 0 \\
\hline Aljouf & 497509 & 12 & 1770 & 1 & 1 & 0 & 1 & 0 & 2 & 0 & 0 \\
\hline TOTAL & $\mathbf{3 1 7 4 2 3 0 8}$ & $\mathbf{2 7 4}$ & $\mathbf{4 1 2 9 7}$ & $\mathbf{5 8}$ & $\mathbf{7 5}$ & $\mathbf{3 5}$ & $\mathbf{5 5}$ & $\mathbf{2 1}$ & $\mathbf{1 8 6}$ & $\mathbf{6 5}$ & $\mathbf{1 8 6}$ \\
\hline
\end{tabular}

About $68 \%$ of nuclear medicine examinations is done in one city (Riyadh), about $85 \%$ of nuclear medicine examinations is done in 2 areas of 13 administrative areas (Riyadh and Makkah) and about 94\% of all examinations are done in 3 areas of the country (Riyadh, Makkah and Shrqiyah).

\section{PET/CT Examinations:}

There are about 18013 PET/CT examinations performed mainly in 2 cities Riyadh and Dammam; 15813 PET/CT examinations (87.4\%) in Riyadh and 2200 PET/CT examinations (12.2\%) in Dammam. Only 80 cases of PET/CT were done in one center in Jeddah as FDG is being delivered from Dubai.

Table 2: Number of examinations performed in all NM services across Saudi Arabia during 2017.

\begin{tabular}{|l|c|c|c|c|c|}
\hline & & \multicolumn{4}{|c|}{ EXAMINATIONS } \\
\hline Region & Population & General NMI & Cardiac & PET/CT & Total (\%) \\
\hline Riyadh & 8002100 & 21397 & 8937 & 15813 & $46147(67.7)$ \\
\hline Makkahh & 8325304 & 8524 & 2878 & 80 & $11482(16.8)$ \\
\hline Madina & 2080436 & 1661 & 201 & 0 & $1862(2.7)$ \\
\hline Qasim & 1387996 & 921 & NA & 0 & $921(1.4)$ \\
\hline Sharqiyah & 4780619 & 3974 & 291 & 2200 & $6465(9.5)$ \\
\hline Aseer & 2164172 & 831 & NA & 0 & $831(1.2)$ \\
\hline Tabouk & 890922 & 347 & 80 & 0 & $427(0.6)$ \\
\hline Hail & 684619 & 0 & 0 & 0 & 0 \\
\hline Alshamalya & 359235 & 0 & 0 & 0 & 0 \\
\hline Jazan & 1533680 & NA & NA & 0 & 0 \\
\hline Najran & 569332 & NA & NA & 0 & 0 \\
\hline Baha & 466384 & 0 & 0 & 0 & 0 \\
\hline Aljouf & 497509 & 0 & 0 & 0 & 0 \\
\hline Total & 31742308 & 37655 & $\mathbf{1 2 3 8 7}$ & 18093 & $68135(100)$ \\
\hline
\end{tabular}

The average number of exams per unit PET/CT was 861 studies/unit during 2017. When we adjusted for the population there were 55.6 PET/CT examinations per 100,000 people.

\section{SPECT and SPECT/CT Examinations:}

Across Saudi Arabia, about 37655 examinations of general nuclear medicine (GNM) and 12387 examinations of cardiac NM during 2017, about $61 \%$ of these studies done in Riyadh. The average number of general and cardiac exams per unit was 556 examinations per unit SPECT or SPECT/CT. When we adjusted for the population there were 152 examinations per 100,000 people.

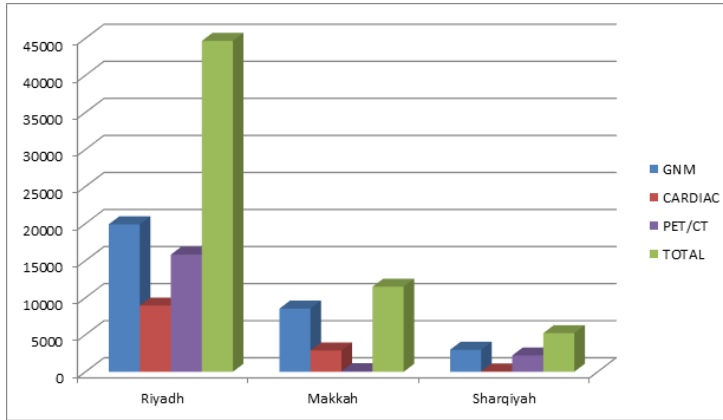

Figure 2: Distributions of NM examinations among the biggest 3 regions of Saudi Arabia.
Personnel:

In Saudi Arabia, nuclear medicine is practiced by nuclear radiologist and nuclear medicine physicians. By the end of 2017, there were about 65 physicians all over the country. The Saudi physicians with board certified Nuclear Medicine are not more than 9 doctors. Across the country there were about 186 technologists with minimum bachelor certification in radiography. By the end of 2017 we found 41 medical physicists, 9 radiopharmacists and 51 nurses.

\section{Cyclotrons and Radiopharmaceuticals:}

Currently there are 7 cyclotrons in Saudi Arabia leaded by King Faisal Specialist hospital and research center in Riyadh which has 3 cyclotrons:

1- CS30 cyclotron from Cyclotron Corporation(USA), Beam energy $27 \mathrm{MeV}$, beam current $150 \mathrm{uA}$, and capable of accelerating 4 particles, proton, deuteron, helium and alpha. (one of few cyclotrons that accelerate these particles), Installed in 1979, start production 1982.

2- RDS cyclotron (Siemens, USA), Beam energy $11 \mathrm{MeV}$, beam current $60 \mathrm{uA}$, accelerate only protons, installed 2005, start production 2006

3- Cyclon 30 from IBA (Belgium), Beam energy $30 \mathrm{MeV}$, Beam current $350 \mathrm{uA}$, and capable of accelerating protons, installed in 2010 , start production 2011

Targets and Radioisotopes for radiopharmaceuticals produced by these cyclotrons:

1- $\mathrm{Tl}-201 \mathrm{TlCl}$

2- $\mathrm{In}-111 \mathrm{InCl} 3$

3- $\mathrm{Ga}-67 \mathrm{GaCl} 3$ and $\mathrm{Ga}-67$ citrate

4- $\mathrm{Rb}-81 / \mathrm{Kr}-81$ generator

5- I-123 NaI (capsules and oral solution)

6- I-124 NaI (capsules and oral solution)

7- F-18FDG

8- F-18 FDOPA

9- F-18 Fcholine

$10-\mathrm{F}-18 \mathrm{NaF}$

11- N-13 ammonia

12- $\mathrm{Cu}-64 \mathrm{CuCl} 2$ and $\mathrm{Cu}-67 \mathrm{CuCl} 2$ (for research)

13- $\mathrm{Zr}-89 \mathrm{ZrCl} 4$ (for research)

14- C-11 (for research)

Other cyclotron in Saudi Arabia which is mainly for F-18 FDG:

1- King Fahad Spec. Hosp. Dammam, IBA $18 \mathrm{MeV}$ cyclotron, they produce FDG-18 and others in small quantity.

2- Saad Spec. Hosp. AlKhobar, RDS cyclotron (Siemens, USA), Beam energy $11 \mathrm{MeV}$. produce FDG-18 and others in small quantity (currently out of service)

3- King Saud University, Riyadh, ACSi $24 \mathrm{MeV}$, from Canada, still in the installation phase.

4- King Abdulaziz University, Jeddah, GE $16.5 \mathrm{MeV}$, from USA, still in the installation phase.

\section{Nuclear Medicine Training:}

There is no recognized NM residency training program yet in Saudi Arabia. However, nuclear medicine is a part of radiology residency training program which is not less than 4 month training in four years. There is a national post residency fellowship of 2 years held in combination between KFSHRC and NGH in Riyadh.

Some of Saudi nuclear medicine physicians make their residency and fellowship trainings in some well-organized institutions around the world with full governmental sponsorship and scholarship.

Saudi Society of Nuclear Medicine (SSNM) is held under umbrella of King Abdul-Aziz University is currently not active due to some administrative obstacles.

\section{Conclusions and Recommendations:}

There is a need to know the current distribution of nuclear medicine services in order to recognize the regions of deficient coverage and to rectify this in future planning.

Although nuclear medicine services are available in most Saudi Arabia regions, there is obvious deficiency in NM centers in multiple regions, mainly in north and south regions. The PET/CT machines are only available in 3 regions within the kingdom, partially due to overcrowding of Cyclotrons in Riyadh. 
Activation of Saudi Society of Nuclear Medicine (SSNM) is mandatory for establishing well recognized Nuclear Medicine residency training programs and other academic and scientific activities.

\section{REFERENCES:}

Delbeke, D., \& Segall, G. M. (2011). Status of and Trends in Nuclear Medicine in the United States. Journal of Nuclear Medicine, 52 (Supplement 2), 24S-8S. https://doi.org/10.2967/jnumed.110.085688

2. The General Authority for Statistics in Saudi Arabia https://www.stats.gov.sa/en/node

Gremillet, E., Lemaire, B., Prigent, A., \& Vuillez, J.-P. (2013). Nuclear medicine training and practice in France. European Journal of Nuclear Medicine and Molecular Imaging, 40(6), 976-978. https://doi.org/10.1007/s00259-013-2352-8 